\title{
Study Of The Relation Between Helicobacter Pylori Infection And Gastric Interleukin (8) In Patients With Chronic Liver Disease
}

\author{
Mohsen M El-Khayat, *Zeinab N Said, Gamal S El-Deeb, \\ Hany S Sabry \& **Mamdoh M Radwan.
}

Tropical medicine $\& * *$ pathology departments, faculty of medicine-Menoufia

University, *Microbiology department, faculty of medicine (for girls)

Al Azhar University

\begin{abstract}
Helicobacter pylori (H pylori) is a gram negative spirally shaped bacterium. It is known to be the most common important cause of gastritis, peptic ulcer, non ulcer dyspepsia and gastric carcinoma. The frequency and importance of gastric mucosal lesion in patients with chronic liver disease (CLD) have been increasingly recognized in recent years. IL-8 a potent leukocyte chemo-attractant cytokine produced by $\mathrm{H}$ pylori. It promotes polymorphnuclear leucocytes (PMNs) and mononuclear cells (MNCs) accumulation in gastric mucosa.This work aimed to clarify the relation between $\mathrm{H}$ pylori and IL-8 production in various chronic liver disease (CLD) lesions. Eighty patients were included in this study, 50 with CLD and 30 dyspeptic patients without CLD. Gastric mucosal biopsies were examined histopathologically for $\mathrm{H}$ pylori, cellular infiltration and associated pathology, together with culture of $\mathrm{H}$ pylori and assessment of IL-8 level in gastric tissue supernatant.

30/50 (60\%) CLD patients, 10/15 (66.6\%) patients with non gastric dyspepsia, and $14 / 15(93.3 \%)$ patients with gastric dyspepsia were positive for $\mathrm{H}$ pylori. There was no relationship between the prevalence of H pylori and the aetiology of CLD.

No significant difference was observed in CLD patients' group as regard to H pylori and Child grading, degree of varices, gastric or liver histopathology. Statistical difference in $\mathrm{H}$ pylori prevalence between patients with CLD and those with gastric dyspepsia was significant. IL-8 showed significant increase in $\mathrm{H}$ pylori positive vs $\mathrm{H}$ pylori negative patients. Positive correlation was found between $\mathrm{H}$ pylori density and tissue IL-8 and cellular infiltration. In conclusion the liver status does not play a role in the prevalence of $\mathrm{H}$ pylori infection, further studies to investigate the relation between virulent $\mathrm{H}$ pylori and IL-8 are needed.
\end{abstract}

\section{Introduction}

$\mathrm{H}$ pylori associated gastritis is fundamentally a bacterial infection of the gastroduodenal mucosal surface and as such is characterized by mucosal infiltration of PMNs and MNCs (Yamaoka, et al., 1998). In $\mathrm{H}$ pylori infection, the cellular infiltrate contains effectors of the immune response, including $\mathrm{CD} 4+$ and. CD8+ $\mathrm{T}$ lymphocytes, B-lymphocytes, plasma cells, monocytes, mast cells and eosinophils (Dixon, et al., 1996). 
Neutrophil activity is an almost universal phenomenon in $\mathrm{H}$ pylori gastritis (Davies, et al., 1994). It is a very sensitive indicator of the presence or absence of $\mathrm{H}$ pylori and disappears within days of cure of $\mathrm{H}$ pylori infection (Graham, 1994). The density of intraepithelial neutrophils has been correlated with the extent of mucosal damage and with the intensity of $\mathrm{H}$ pylori infection (Fiocca et al, 1992,

Edit and Stolte, 1994). The presence of neutrophil polymorphs in a background of chronic inflammation is a measure of continuing acute inflammation. The normal gastric mucosa contains only individual scattered chronic inflammatory cells (mononuclear cells) in the lamina propria. Thus, any increase indicates chronic gastritis.

Inflammatory cytokines are playing critical roles in inflammation associated with gastrointestinal infections specially $\mathrm{H}$ pylori infection of gastric mucosa (Yamaoka 1998). The migration and activation of inflammatory cells into the mucosa is thought to be related to expression of various cytokines (Crabtree et al., 1993 and Yamaoka et al., 1995, 1996). Over the past 15 years a new family of cytokines has been characterized whose members have chemoattractant activity for leukocytes and fibroblast. (chemokines). They appear to play a crucial role in attracting specific types of cells into sites of tissue injury and inflammation (Daniel 2001).

Interleukin 8 (IL-8) is secreted by monocytes, macrophages, $\mathrm{T}$. lymphocytes, neutrophils, fibroblast, keratinocyte and hepatocytes. It acts as a chemotactic factor for neutrophils, $\mathrm{T}$ lymphocytes subsets and basophils. It activates neutrophils to release lysosomal enzymes and primarily induces neutrophils adherence to endothelial cells (Martin et al 2002). A number of studies have investigated IL8 , which is known to be a neutrophil chemotactic factor, and have shown an association between levels of $\mathrm{H}$ pylori infection and IL-8 mRNA (Yamaoka et al., 1995, 1996) or IL-8 protein (Crabtree et al., 1993, Yamaoka et al., 1997).

IL-8 and other interleukins attract neurtrophils which migrate from the capillaries, through the lamina propria and emerge between the epithelial cells. The most common cause of peptic ulcer may be the migration of these many neutrophils with subsequent release of their digestive products (Ge and Taylor 1999). Wu et al., (1998) added that $H$ pylori infection causes almost all uncomplicated duodenal ulcers and more than $80 \%$ of gastric ulcers. Yoshikawa et al., (1999) found that The Cag A genome in gastric Juice was detected in $98 \%$ of patients with peptic ulcer.

In the last few years, a higher prevalence of $\mathrm{H}$ pylori infection has been described in patients with liver cirrhosis than in age and sex matched controls (Siringo, et al., 1997,). Further studies, however , are necessary in order to verify whether the association is causal or occasional. Furthermore, it is unclear whether the association has a clear pathological significance as the available data show no relation between $\mathrm{H}$ pylori infection status and the severity of liver disease (Farinati, et al., 1998). However, the fact that infected patients have higher blood concentrations of ammonia and that eradication of the bacterium results in a significant reduction in ammonia levels is interesting (Miyaji, 1997 ). H pylori urease activity in the stomach of cirrhotic patients has been proposed to represent a significant source of ammonia, contributing to the 
development of hepatic encephalopathy (Attili, et al., 1994, Gubbins, et al., 1993).

The aim of this work is to clarify the relation between $\mathrm{H}$ pylori infection and chemokine (IL-8) in different gastric lesions in patients with different forms of liver disease compared to those with normal liver status.

\section{Subjects, Materials and Methods}

This study was conducted on 80 patients admitted to Tropical Medicine Department, Menoufiya University Hospitals in the period from January 1999 to December 2000. They were divided into 50 patients with chronic liver disease (CLD) and 30 dyspeptic control subjects with normal liver status. The diagnosis of CLD was confirmed by a combination of clinical, biochemical, imaging methods and liver biopsy if indicated. The CLD patients were included in the study regardless of the presence or absence of upper gastrointestinal symptoms. They comprised group I, their mean age was $40.7 \pm 9.28$ ranging from 21-59 years. They were 38 $(76 \%)$ males and $12(24 \%)$ females.

Thirty age and sex matched dyspeptic subjects with no evidence of previous liver disease were included in this study as a control group. They comprised group II. They were classified according to their endoscopic findings into: Group IIa: gastric dyspepsia group (abnormal endoscopic findings). Group IIb: non gastric dyspepsia group (normal endoscopic findings). Their mean age was $37 \pm 7.12$ ranging from 23-60 years. They were 26.(86.7\%) males and 4 (13.3\%) females.

The severity of CLD in group I was determined and each patient was classified using Pugh's modification of Child's classification (Table 1).

Table 1: Pugh's modification of Child's classification (Pugh, 1973)

\begin{tabular}{|c|c|c|c|}
\hline & Score 1 point & Score 2 point & Score 3 point \\
\hline Serum bilirubin & Below 2 & $2-3$ & Over 3 \\
\hline $\begin{array}{l}\text { Prolongation of prothrombin } \\
\text { time (second) }\end{array}$ & $1-4$ & $4-6$ & $>6$ \\
\hline Albumin $(\mathrm{gm} / \mathrm{dl})$ & Over 3.5 & $3-3.5$ & Under 3 \\
\hline Ascites & None & Slight & $\begin{array}{l}\text { Moderate or } \\
\text { more }\end{array}$ \\
\hline $\begin{array}{l}\text { Portosystemic encephalopathy } \\
\text { (grades) }\end{array}$ & None & 1 and 2 & 3and 4 \\
\hline
\end{tabular}

Grade $A=5$ or 6 points

Grade $B=7-9$ points

Grade $\mathrm{C}=10-15$ points

All patients underwent eosphagogastroduodenoscopy where four biopsy specimens were taken from both antrum and corpus, two were used for histological examination, one for $\mathrm{H}$ pylori culture and one for IL -8 measurement. The presence of $\mathrm{H}$ pylori was determined by culture and 
histological examination. Patients were classified as $\mathrm{H}$ pylori positive if at least one of the examinations gave a positive result.

\section{Histology}

The biopsy specimens were fixed in $10 \%$ buffered formalin, embedded in paraffin wax, Sections were stained with haematoxylin and eosin and modified Giemsa stain and were examined for small curved bacilli on the mucosal surface and the density of $\mathrm{H}$ pylori was scored based on average density on surface and graded from 0 to 3+; G0: no characteristic bacilli; G1+: occasional curved bacilli; G2+: Scattered bacilli in most high power field; G3+: numerous bacilli in most high power field (Yamaoka et al., 1998).

Also MNCs and PMNs density were evaluated and graded from 0 to 3 using visual analogue scale, according to the Updated Sydney system (Dixon et al., 1996). For analysing the relation between the histological findings and the expression patterns of chemokines, we used the biopsy specimens from a mucosal site adjacent to the site where the biopsy specimens for chemokine measurements were obtained.

\section{H pylori Culture}

One gastric biopsy was placed in thioglycolate broth and transferred to the laboratory. The biopsy specimens were immediatly homogenized using tissue homogenizer to ensure equal distribution of tissue fragments. The minced homogenate was cultured on Dent medium, formed of: Colombia Blood agar base with $10 \%$ defibrinated sheep blood ii-Helicobacter pylori selective supplement (Dent) (SR 147 E) having the following formula: (Vancomycin $5.0 \mathrm{mg}$, Trimethoprim 2.5mg, Cefsulodin 2.5mg. Amphotericin B 2.5mg) and incubated at $37 \mathrm{C}^{\circ}$ under microaerophilic conditions for 3-5 days, using the anaerobic jar with a catalyst and the Gas Generating Kit Campylobacter System (Campy Gen ${ }^{\mathrm{TM}}$-Oxoid-BR 056A). H Pylori colonies appear as nonhaemolytic, tiny, circular, 1 to $2 \mathrm{~mm}$. in diameter, grey translucent, discrete and convex colonies on blood agar plates. Colonies that exhibited characteristics of colonial morphologies were identified as H Pylori by: Gram stain, positive catalase, oxidase and urease reactions (Cheesbrough M, 2000).

\section{IL-8 Measurement}

The biopsy specimens were placed in $1.5 \mathrm{ml}$ of phosphate buffered saline (PBS) $\mathrm{pH} \quad 7.4$ and were immediately homogenized using ultrasonic homogenizer. Aliquots of homogenate supernatants were obtained by centrifugation at $10.000 \mathrm{rpm}$ for 10 minutes and were stored at $-70^{\circ} \mathrm{C}$ until assay for total proteins by a modified Lowry method using commercially available kit (Spinreact - Spain) and for IL-8 by ELISA technique using kits supplied by (Diaclone - France) \& following the manufacturer instructions. The mucosal level of IL-8 was expressed as pg/mg biopsy protein and data were expressed as median and range.

\section{Statistical Analysis and Data Presentation}

Two tailed students' $\mathrm{t}$ and $\chi^{2}$ tests were used to compare different parameters. Correlations were determined using (r) coefficient of variation. Probability (p) values of less than or equal to 0.05 were considered significant. 


\section{Results}

The presence of $\mathrm{H}$ pylori was determined by culture and histopathology. Patients were classified as $\mathrm{H}$ pylori positive if at least one of the examinations gave a positive result (Fig $1 \mathrm{a} \&$ b). It was 54/80 (67.5\%) where $30 / 50(60 \%)$ CLD patients, and 24/30 $(80 \%)$ control group were $\mathrm{H}$ pylori positive. H pylori positivity showed no significant difference between both groups as regard to sex $(\mathrm{P}>0.05)$ while age distribution showed a significant high positivity of $\mathrm{H}$ pylori in older than middle aged patients of both groups $(\mathrm{P}<0.01)$ (Table 2).

The main complaints of $\mathrm{H}$ pylori positive CLD patients were epigastric pain and sense of fullness. While $\mathrm{H}$ pylori positive subjects in control group were mainly suffering from epigastric pain and heartburn. No significant difference between $\mathrm{H}$ pylori positive patients with and without CLD as regard to symptoatology could be detected $(\mathrm{P}>0.05)$.

Endoscopic findings studied in both groups showed that in GI there were $12(24 \%)$ with normal endoscopic findings, while 38 (76\%) showed overlapping findings in form of gastritis $4(8 \%)$, deudenitis $7(14 \%)$, gastric ulcer $9(18 \%)$, duodenal ulcer $6(12 \%)$, oesphageal varices $25(50 \%)$, lower end oesphagitis $13(26 \%)$, reflux oesphagitis $2(4 \%)$, and gastric mass one $(2 \%)$ while in GII there were $6(20 \%)$ with gastritis, 3 (10\%) with deudenitis, 3 $(10 \%)$ with gastric ulcer, $3(10 \%)$ with duodenal ulcer, 2 (6.6\%) with lower end oesphagitis, no one showed gastric mass and one only (3.3\%) with reflux oesphagitis, those comprised group IIa (Gastric dyspepsia group). While there were $15(50 \%)$ with normal endoscopic findings. They were considered non gastric dyspeptic group (group IIb) (Table 3).
Histopathological grading of $\mathrm{H}$ pylori positivity in different studied groups showed that $\mathrm{H}$ pylori positivity is highly significant in GIIa (gastric dyspepsia group) while moderate increase was detected in GI and GIIb (Table 4). A high significant difference could be detected as regard to PMNs \& MNCs infilteration in gastric tissue, where they were increased in GIIa $\mathrm{P}<0.01$ (Table 5).

Looking for the aetiology of liver disease, clinical, laboratory and histopathological findings showed that 17 (34\%) had schistosomiasis, 9 patients $(18 \%)$ had cirrhosis. $12(24 \%)$ had chronic hepatitis and lastly 12 (24\%) showed mixed picture. No significant difference could be detected between $\mathrm{H}$ pylori positive and $\mathrm{H}$ pylori negative patients as regard to liver disease aetiology $\mathrm{P}>0.05$ (Table 6).

Statistical analysis of $\mathrm{H}$ pylori positivity with the severity of liver disease in CLD patients following Pough modification of Child classification, showed no statistical difference in $\mathrm{H}$ pylori positivity and different grades of liver affection $\mathrm{P}>0.05$ (Table 7).

Studying the relation between $\mathrm{H}$ pylori positivity and degree of oesophageal varices in CLD patients showed no significant difference $(\mathrm{P}>0.05)$.

Gastric histopathological findings in group I showed that there were 8 (16\%) with normal mucosa, $25(50 \%)$ with chronic atrophic gastritis, 9 (18\%) with atrophic dysplasia, $7(14 \%)$ with reactive gastritis while only one patient (2\%) with gastric carcinoma. When the positivity of $\mathrm{Hp}$ was statistically analysed in relation to gastric histopathology no significant difference could be detected $\mathrm{P}>0.05$ (Figure 2). As expected relation between $\mathrm{H}$ pylori positivity and PMNs \& MNCs in CLD 
patients was highly significant (Table 8).

IL-8 showed significant difference between GI and GIIa $\mathrm{P}<0.01$ (Table 9). And it showed a significant increase in $\mathrm{H}$ pylori positive vs $\mathrm{H}$ pylori negative patients in G I\&IIa (Table 10). A significant positive correlation was found between $\mathrm{H}$ pylori positivity,
PMNs, MNCs and IL-8 level in CLD patients $\mathrm{P}<0.05$ (Figur $3 \mathrm{a}, \mathrm{b}, \mathrm{c}$ ). On the other hand, no significant relation could be detected between mucosal IL-8 level and gastric histopathology or endoscopic findings in CLD patients P> 0.05 except for, significant increase in patients with deudenal ulcer $p<0.05$.

Table (2): Statistical analysis of demographic data in relation to $\mathrm{H}$ pylori in the studied patients

\begin{tabular}{|c|c|c|c|c|c|c|c|c|c|c|}
\hline \multirow[b]{2}{*}{ Sex } & \multicolumn{5}{|c|}{$\overline{\text { GI }}$} & \multicolumn{5}{|l|}{$\overline{\text { GII }}$} \\
\hline & HP+ & HP- & Total & $\mathrm{X}^{2}$ & $\mathrm{P}$ & HP+ & HP- & Total & $\mathrm{X}^{2}$ & $\mathrm{P}$ \\
\hline Male & 26 & 12 & 38 & \multirow{2}{*}{3.28} & \multirow{2}{*}{$>0.05$} & 21 & 5 & 26 & \multirow{2}{*}{0.07} & \multirow{2}{*}{$>0.05$} \\
\hline Female & 4 & 8 & 12 & & & 3 & 1 & 4 & & \\
\hline \multicolumn{11}{|l|}{ Age } \\
\hline $20-40$ & 9 & 14 & 23 & \multirow{3}{*}{7.73} & \multirow{3}{*}{$<0.01$} & 7 & 4 & 11 & \multirow{3}{*}{2.91} & \multirow{3}{*}{$<0.01$} \\
\hline $40-60$ & 21 & 6 & 27 & & & 17 & 2 & 19 & & \\
\hline Total & 30 & 20 & 50 & & & 24 & 6 & 30 & & \\
\hline
\end{tabular}

Table (3): Endoscopic findings in the studied patients.

\begin{tabular}{|l|l|l|l|l||}
\hline \multirow{2}{*}{ Endoscopic Findings } & \multicolumn{2}{|l|}{ GI No=50 } & \multicolumn{2}{l|}{ GII No=30 } \\
\cline { 2 - 5 } & No & \% & No & \% \\
\hline \hline Normal findings & 12 & 24 & 15 & 50 \\
\hline Gastritis & 4 & 8 & 6 & 20 \\
\hline Deudenitis & 7 & 14 & 3 & 10 \\
\hline Gastric ulcer & 9 & 18 & 3 & 10 \\
\hline Deodenal ulcer & 6 & 12 & 3 & 10 \\
\hline Oesphageal varices & 25 & 50 & -- & -- \\
\hline Lower end oesphagitis & 13 & 26 & 2 & 6.6 \\
\hline Reflux & 2 & 4 & 1 & 3.3 \\
\hline Mass & 1 & 2 & -- & -- \\
\hline
\end{tabular}


Table (4): Statistical analysis of histopathological grading of $\mathrm{H}$ pylori postivity in the studied patients.

\begin{tabular}{|c|c|c|c|c|c|c|c|}
\hline \multicolumn{2}{|c|}{ Hp Grading } & GI & GIIa & GIIb & Total & $\mathrm{X} 2$ & $\mathrm{P}$ \\
\hline \multirow{4}{*}{ Hp } & -ve & 20 & 1 & 5 & 26 & \multirow{4}{*}{23.47} & \multirow{4}{*}{$<0.01 *$} \\
\hline & + & 1 & 0 & 5 & 6 & & \\
\hline & ++ & 22 & 9 & 5 & 36 & & \\
\hline & +++ & 7 & 5 & 0 & 12 & & \\
\hline \multicolumn{2}{|c|}{ Total } & 50 & 15 & 15 & 80 & & \\
\hline
\end{tabular}

* Highly significant

Table (5): Statistical analysis of gastric cellular infiltration in the studied patients

\begin{tabular}{|c|c|c|c|c|c|c|c|}
\hline \multicolumn{2}{|c|}{$\begin{array}{l}\text { MNL } \\
\text { Grading }\end{array}$} & GI & GIIa & GIIb & Total & $X^{2}$ & $\mathrm{P}$ \\
\hline \multirow{4}{*}{ MNL } & $\overline{0}$ & 7 & 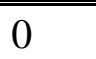 & 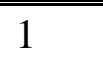 & 8 & \multirow{4}{*}{19.69} & \multirow{4}{*}{$<0.01$} \\
\hline & 1 & 21 & 1 & 7 & 29 & & \\
\hline & 2 & 18 & 7 & 6 & 31 & & \\
\hline & 3 & 4 & 7 & 1 & 12 & & \\
\hline \multirow{4}{*}{$\mathrm{PMN}$} & 0 & 10 & 0 & 1 & 11 & \multirow{4}{*}{13.21} & \multirow{4}{*}{$<0.01$} \\
\hline & 1 & 14 & 0 & 5 & 19 & & \\
\hline & 2 & 18 & 10 & 7 & 35 & & \\
\hline & 3 & 8 & 5 & 2 & 15 & & \\
\hline \multicolumn{2}{|l|}{ Total } & 50 & 15 & 15 & 80 & & \\
\hline
\end{tabular}

Table (6): Statistical analysis of $\mathrm{H}$ pylori postivity and aetiology of liver diseases in CLD patients

\begin{tabular}{|c|c|c|c|c|c|}
\hline \multirow{2}{*}{ Cause of disease } & \multicolumn{2}{|c|}{ H p positivity } & \multirow[b]{2}{*}{ Total } & \multirow[b]{2}{*}{$X^{2}$} & \multirow[b]{2}{*}{$\mathrm{P}$} \\
\hline & $\mathrm{H} \mathrm{p}+$ & $\mathrm{H} \mathrm{p}-$ & & & \\
\hline Schistosomiasis & 11 & 6 & 17 & 0.06 & $>0.05$ \\
\hline Cirrhosis & 6 & 3 & 9 & 0.2 & $>0.05$ \\
\hline Mixed & 8 & 4 & 12 & 0.29 & $>0.05$ \\
\hline Chronic hepatitis & 5 & 7 & 12 & 1.4 & $>0.05$ \\
\hline Total & 30 & 20 & 50 & & \\
\hline
\end{tabular}


Table (7): Statistical analysis of $\mathrm{H}$ pylori postivity and severity of liver affection in CLD patients

\begin{tabular}{|l|l|l|l|l|l||}
\hline \multirow{2}{*}{ Child grade } & \multicolumn{2}{|l|}{$\mathrm{H} \mathrm{p}$ postivity } & \multirow{2}{*}{ Total } & \multirow{2}{*}{$\mathrm{X}^{2}$} & \multirow{2}{*}{$\mathrm{P}$} \\
\cline { 2 - 6 } & $\mathrm{H} \mathrm{p}+$ & $\mathrm{H} \mathrm{p}-$ & & & \\
\hline \hline Child A & 17 & 13 & 30 & 0.35 & $>0.05$ \\
\hline Child B & 9 & 5 & 14 & 0.15 & $>0.05$ \\
\hline Child C & 4 & 2 & 6 & 0.13 & $>0.05$ \\
\hline Total & 30 & 20 & 50 & & \\
\hline
\end{tabular}

Table (8): Statistical analysis of gastric cellular infiltration and $\mathrm{H}$ pylori positivity in CLD patients

\begin{tabular}{|c|c|c|c|c|c|c|c|c|}
\hline \multirow{2}{*}{\multicolumn{2}{|c|}{ Cells }} & \multicolumn{4}{|c|}{$\mathrm{Hp}$} & \multirow{2}{*}{ Total } & \multirow{2}{*}{$X^{2}$} & \multirow{2}{*}{$\mathrm{P}$} \\
\hline & & -ve & + & ++ & +++ & & & \\
\hline \multirow{4}{*}{ PMNs } & 0 & 10 & 0 & 0 & 0 & 10 & \multirow{4}{*}{47.77} & \multirow{4}{*}{$<0.01$} \\
\hline & 1 & 8 & 1 & 5 & 0 & 14 & & \\
\hline & 2 & 1 & 0 & 15 & 2 & 18 & & \\
\hline & 3 & 1 & 0 & 2 & 5 & 8 & & \\
\hline \multirow{4}{*}{ MNCs } & 0 & 7 & 0 & 0 & 0 & 7 & \multirow{4}{*}{56.62} & \multirow{4}{*}{$<0.01$} \\
\hline & 1 & 13 & 1 & 7 & 0 & 21 & & \\
\hline & 2 & 0 & 0 & 15 & 3 & 18 & & \\
\hline & 3 & 0 & 0 & 0 & 4 & 4 & & \\
\hline \multicolumn{2}{|l|}{ Total } & 20 & 1 & 22 & 7 & 50 & & \\
\hline
\end{tabular}

Table (9): Statistical analysis of gastric IL-8 in the studied groups

\begin{tabular}{|c|c|c|c|c|c|}
\hline \begin{tabular}{|l} 
IL8 \\
(pg/mg)
\end{tabular} & $\mathbf{N}$ & Mean & SD & t. & $P$ value \\
\hline GI & 50 & 70.994 & 18.448 & \multirow{2}{*}{-4.168} & \multirow{2}{*}{$\begin{array}{l}\mathrm{P}^{*} \\
<0.01\end{array}$} \\
\hline GII a & 15 & 103.333 & 43.985 & & \\
\hline GII b & 15 & 70.713 & 11.798 & 0.055 & $\begin{array}{l}\mathrm{P} \\
>0.05\end{array}$ \\
\hline
\end{tabular}


Table (10): Statistical analysis of gastric IL-8 level and $H$ pylori positivity in the studied patients

\begin{tabular}{|l|l|l|l||}
\hline Group & H p(+) & H p (-) & P value \\
\hline \hline GI & $80.3 \pm 7.9$ & $62.2 \pm 10.2$ & $<0.05$ \\
\hline GII a & $114 \pm 24.3$ & $85 \pm 18.1$ & $<0.01$ \\
\hline GII b & $74.6 \pm 10$ & $68.5 \pm 9.2$ & $>0.05$ \\
\hline
\end{tabular}

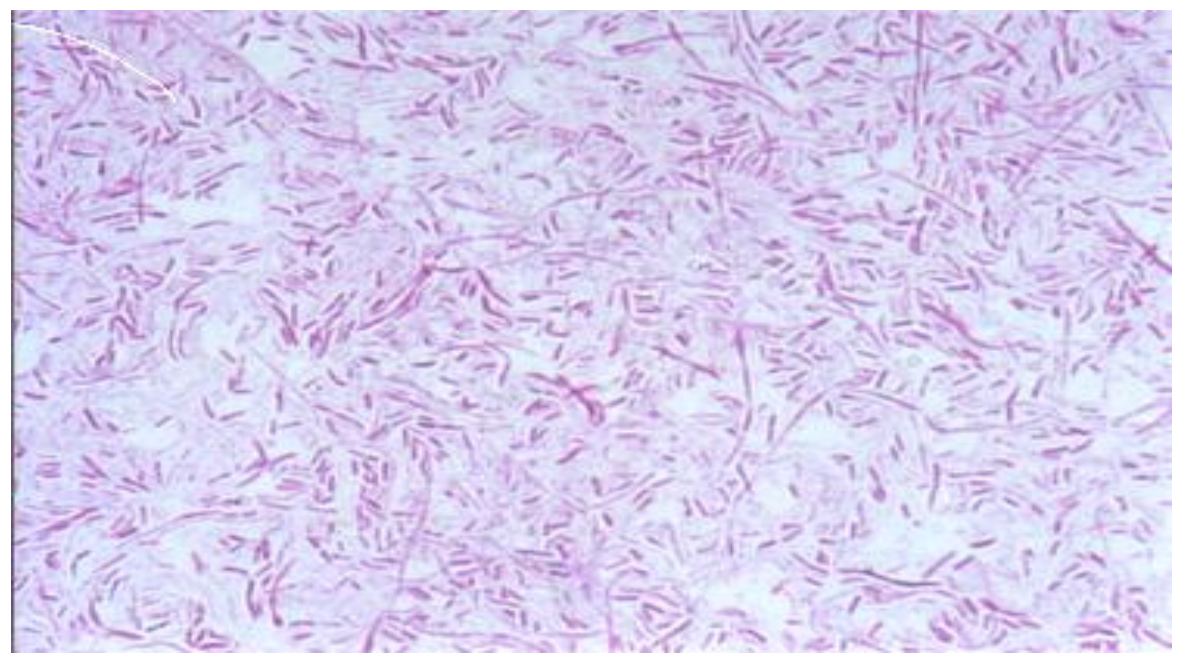

Figure (1a): H pylori organisms in Gram stain under light microscopy (oil immersion lens X 100)

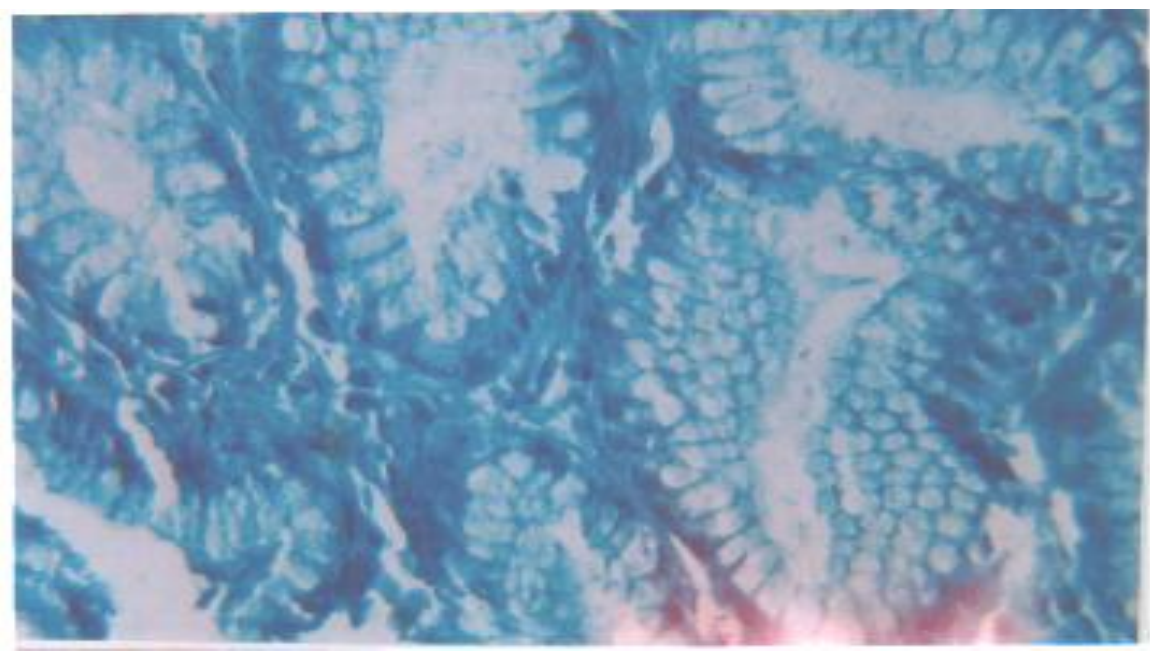

Figure (1b): Few number of $\mathrm{H}$ pylori organisms inside the Lamina in some gastric tubules (modified Giemsa stain $\mathrm{x} 400$ ) 
Mohsen M El-Khayat, et al

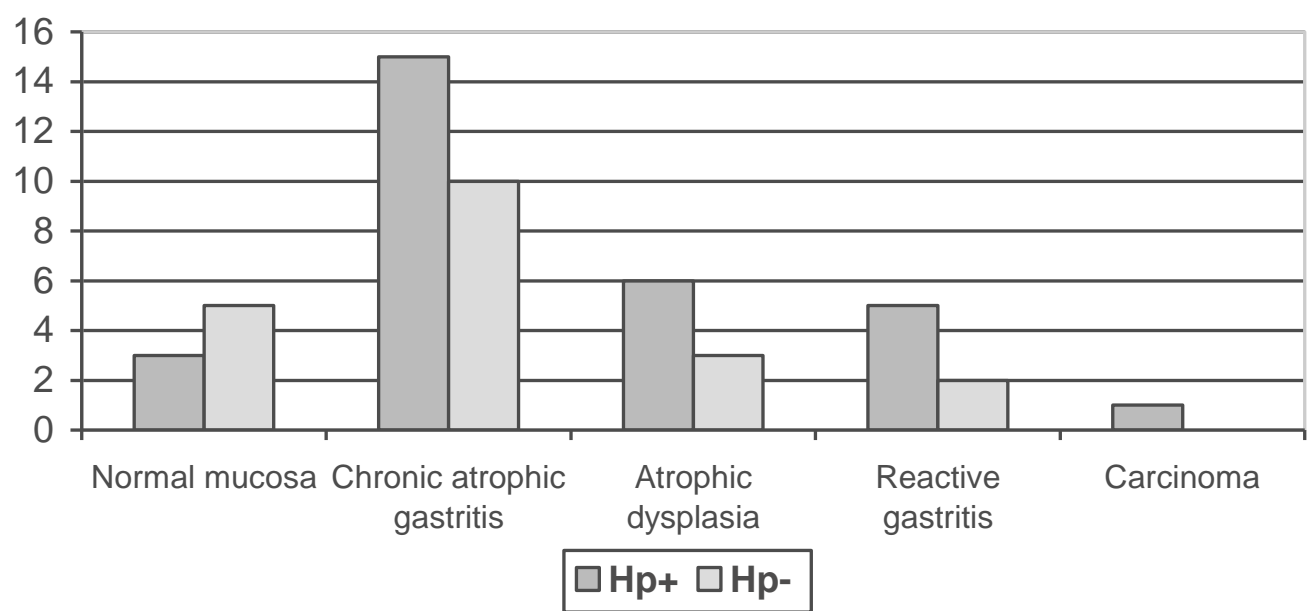

Figure (2): Relation between H pylori positivity and gastric histopathology in CLD patients

(a)

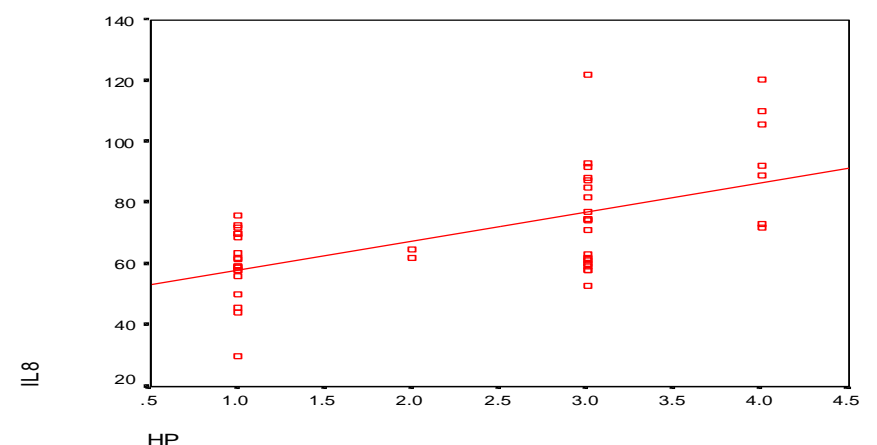

(b)

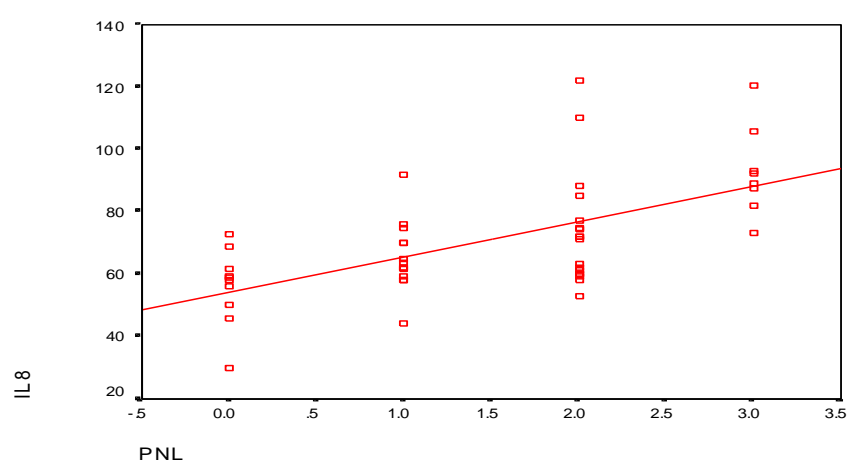

(c)

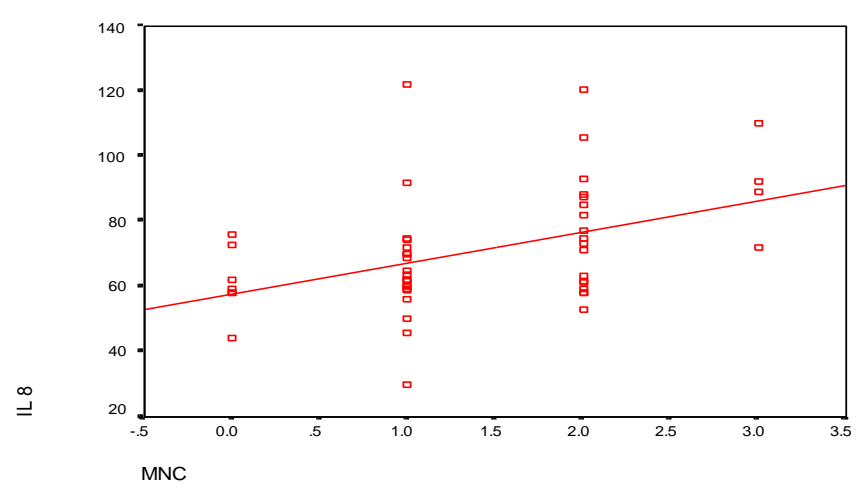

Figure (3): Correlation between H pylori positivity (a) PMNs (b) and MNCs (c) and IL-8 in CLD patien 


\section{Discussion}

$\mathrm{H}$ pylori is a very common pathogen, infecting approximately half the world's population (Pisani et al., 1997). The epidemiology of $\mathrm{H}$. pylori infection differs between the developed and developing worlds. In industrialized countries, infection is acquired at a fairly constant rate of $0.5-2 \% /$ year, reaching a prevalence of $20-40 \%$ in the adult population (Parsonnet, 1995). However, in developing countries, $\mathrm{H}$ pylori is acquired mainly during early childhood at a very fast rate. By the age of 20 years, $70-90 \%$ of the population already infected (Hopkins et al., 1993). In the present study, $\mathrm{H}$ pylori was detected in $67.5 \%$ of the studied patients This was in accordance to previous Egyptian reports suggesting a prevalence of $60-90 \%$ of $\mathrm{H}$ pylori in adults (Mounir et al., 2000, Bassily et al., 1999, Omar et al., 1997 and El Zayadi et al., 1990).

In the present study, $\mathrm{H}$ pylori was less frequent in CLD patients than in control group as its prevalence in CLD was $60 \%$ while in non gastric dyspeptic subjects it was $66.6 \%$ with no significant difference between both groups. It was only significant when comparing CLD patients with gastric dyspeptic subjects $p<0.05$. Balzano et al., (1991), reported that the prevalence of $\mathrm{H}$ pylori in CLD patients was lower than normal population and suggested that the gastric mucosa of patients with portal hypertension may be inhospitable environment for $\mathrm{H}$. pylori. Farianti et al., (1998) added that hypertensive gastropathy might not represent a favourable environment for $\mathrm{H}$ pylori thus making the diagnostic sensitivity of the biopsy lower than expected. However, Calvet et al., (1997), reported that 105 out of 209 cirrhotic patients $(50.2 \%)$ had positive $\mathrm{H}$ pylori IgG and concluded that $\mathrm{H}$ pylori infection in cirrhosis had the same epidemiological pattern as in the general population in Spain. Also, in Egypt, Omar et al., (1997), concluded that there was no relation between $\mathrm{H}$ pylori infection and chronic liver disease. On the other hand Ponzetto et al., (2000), found that the prevalence of $\mathrm{H}$ pylori infection in CLD patients was significantly higher than in age-matched male blood donors and the investigators suggested that $\mathrm{H}$ pylori may be implicated in the pathogenesis and prognosis of cirrhosis in CLD individuals. Also Siringo et al., (1997), suggested that this is due to recurrent admission to hospital and endoscopy which were well-known risk factors for spread of $\mathrm{H}$ pylori infection.

In the present study, there was no significant difference between males and females as regard $\mathrm{H}$ pylori infection either in CLD or control group. The same results were obtained by Calvet et al., (1997), Schmulson et al, (1997) and Omar et al., (1997), while Siringo and his colleagues, (1997) reported a significant increase of $\mathrm{H}$ pylori infection in male cirrhotic patients.

In this study, the prevalence of $\mathrm{H}$ pylori infection increases with age in both studied groups, This finding agreed with the result of Vaira et al., (1997). The increase in frequency of infection in older patients might be due to cumulative risk for infection (Dubois, 1995). On the other hand, Tsai (1998) Omar et al., (1997) and El Ansary (1994) found no difference in $\mathrm{H}$ pylori prevalence between different age groups.

Analysis of dyspeptic symptoms in this study revealed no significant difference between all groups. Also, there were no specific symptoms for $\mathrm{H}$ pylori infection and these was in accordance to Graham et al., (1992) 
who suggested that $20-50 \%$ of patients with positive $\mathrm{H}$ pylori showed dyspeptic symptoms.

In the present study, there was no significant difference between the prevalence of $\mathrm{H}$ pylori infection and aetiology of liver disease. This was in accordance to Tsai (1998) and Siringo et al., (1997) On the other hand, Abd El Hamid et al., (1995) found that, correlating $\mathrm{H}$ pylori status with the aetiology of liver disease revealed that patients with mixed schistosomiasis and cirrhosis had higher prevalence of $\mathrm{H}$ pylori compared with chronic active hepatitis patients.

In the present work, it is evident that chronic atrophic gastritis (50\%) was the predominant gastric histopathology in CLD with $\mathrm{H}$ pylori infection. This was in accordance to (Negrini et al., 1996; and Edit and Stolte, 1994). Despite the fact that $\mathrm{H}$ pylori is known to be non invasive, mucosal infiltration of inflammatory cells have been observed in gastric mucosa. This study showed that PMNs and MNCs infiltration was significantly high with increased $\mathrm{H}$ pylori density. This result was also supported by Kim et al., (1998) who stated that a significant correlation was observed between $\mathrm{H}$ pylori density and histological severity.

In the assessment of whether the positivity of $\mathrm{H}$ pylori varied with increasing severity of CLD. According to Child-Pugh classification, it was found that there was no significant difference in $\mathrm{H}$ pylori positivity in cirrhotic patients with different degrees of severity The same finding was reported by Tsai , (1998), Siringo et al., (1997) and Wu et al., (1995), who found that the prevalence of $\mathrm{H}$ pylori was similar in compensated and decompensated cirrhotic patients, but was not agreement with Naumovski-
Mihalie et al., (2000), who reported that $\mathrm{H}$ pylori infection was higher in Child's class $\mathrm{C}$ group. On the other side, Schmulson et al., (1997), found that the prevalence of $\mathrm{H}$ pylori was inversely related to the Child-Pugh grading. Relating $\mathrm{H}$ pylori prevalence to the oesophageal varices grades revealed no significant relation, these data were supported by Mostafa et al., (1993) Shaheen (1993) and Mc Cormick et al., (1991),

Cytokines are suspected to play a crucial role in pathogenesis of $\mathrm{H}$ pylori associated gastric disease, Takahashi et al., (1998).

In the present study, gastric IL-8 level was significantly higher in patients with gastric dyspepsia than patients with CLD or those subjects with non gastric dyspepsia. Mucosal level of IL-8 in gastric tissue supernatants in subjects with $\mathrm{H}$ pylori infection either with or without CLD was significantly higher in comparison with $\mathrm{H}$ pylori negative patients. The same result was also obtained by Daniel et al., (2001), who added that exposure of gastric epithelial cells to $\mathrm{H}$ pylori infection stimulate the induction of IL-8 secretion as an inflammatory mediator. These findings were consistent with the possibility that $\mathrm{IL}-8$ is playing an important roles in $\mathrm{H}$ pylori associated gastric inflammation (Yamaoka et., al 1998).It is of interest that the mucosal level of IL 8 correlated significantly with $\mathrm{H}$ pylori density as well the cellular infiltration. Ando et al., (1996) stated that $\mathrm{H}$ pylori density may be one of the pathogenic factors causing infiltration of inflammatory cells through elevated IL 8 secretion in gastroduodenal diseases. According to Harris et al.,(1996)H pylori urease and other proteins are capable of activating mononuclear phagocytes and stimul ating them to produce many cytokines 
including IL 8, at the level of gene transcription.

In this study there was a significant correlation between IL-8, MNCs and PMNs infiltration in gastric mucosa suggesting that IL-8 causes severe inflammation. This was also supported by (Yamaoka 1998, Gad allah 2001), They stated that IL-8 produced by $\mathrm{H}$ pylori induce migration to PMNs and MNCs and then subjected to activation by locally secreted IL-8 yielding degranutation and respiratory burst that may be involved in mucosal injury in the stomach.

The present study showed no significant difference in IL-8 level as regard to gastric histopathology in CLD group. This agrees with Yamaoka et al., (1998) as they stated that $\mathrm{H}$ pylori infection increases expression and production of chemokine IL-8 irrespective of gastric pathology.

Also it was found that mucosal level of IL-8 was significantly higher in patients with deudenal ulcer compared with other endoscopic findings in CLD group. This was in accordance to Yamaoka et al., (1998). H pylori damages the mucosa both directly through the urease catalyzed synthesis of ammonia and production of cytotoxins and bacterial enzymes that deplete mucus and damage epithelial cells, and indirectly through the stimulation of local and systemic immune responses (Dixon, et al., 1996).

In conclusion, it appeared from the results of this study that the aetiology or the severity of liver disease could not be related to $\mathrm{H}$ pylori infection. The liver status does not play a role in the prevalence of $\mathrm{H}$ pylori. IL8 showed significant increase in $\mathrm{H}$ pylori positive vs $\mathrm{H}$ pylori negative patients and positive correlation was found between its gastric level and $\mathrm{H}$ pylori density and cellular infiltration.

\section{References}

1. Abdel Hamid A., Khalil K. A., Serwash, A. and Nooman Z. M. (1995): Helicobacter Pylori In Ulcer And Non-Ulcer Dyspepsia Proceeding Of The $2^{\text {nd }}$ Annual Congress Of The Egyptian Society Of Tropical Medicine, Infection And Parasitic Diseases; Abstract (771).

2. Ando, T.; Kusugami, K.; Ohsuga, M.; Shinoda, M.; Sakakibara, M.; Saito, H.; Fukatsu, A.; Ichiyama, S. and Ohta, M. (1996): Interleukin-8 activity correlates with histological severity in $\mathrm{H}$ pylori. Associated Antrol Gastritis, Am J Gastroenterol, 91(6): 1150-6

3. Attili A.F., Rinaldi V., Caschera M., (1994): Helicobacter Pylori: A Major Determinant Of Serum Ammonia Levels In Cirrhotic Patients (Abstract). Hepatology; 20: 110A.

4. Calvet X, Navarro M, Gil M, Mas P, Rivero E,Safeliu I and Brulle E (1997): Seroprevalence And Epidemiology Of Helicobacter Pylori Infection In Patients With Cirrhosis. J Hepatol; 26: 1249-1254

5. Cheesbrough M., (2000): District Laboratory Practice in Tropical Countries part 2- Cambridge University Press; P. 7.18-20-22.

6. Daniel L (2001): Pathologic Characters Of HP In Microbiology Second Edition Boston W C B Mc Grow - Hill.1232-1267

7. Davies G. R., Simmonds N. J.,and Stevens T., (1994): Helicobacter Pylori Stimulates Antral Mucosal Reactive Oxygen Metabolite Production In Vivo. Gut; 35:179-85.

8. Dixon M. F., Genta R. M.M and Yardley J. H., (1996): Classification And Grading Of Gastritis. The Updated Sydney 
System. Am. J Surg Pathol; 20: 1161-81.

9. Dubois A. (1995): Spiral Bacteria In The Human Stomach: The Gastric Helicobacters. Emerging Infectious Diseases; 1 (3): 79.

10. Edit S. And Stolte M. (1994): Antral Intestinal Metaplasia In H. Pylori Gastritis. Digestion. 55/1: (13-18).

11. El - Ansary M. A. F., (1994): Study Of Helicobacter Pylori And Local Immune Response In Upper Gastrointestinal Tract Lesion In Endemic Hepatosplenomegaly Thesis. Faculty Of Medicine, Cairo University.

12. El-Zayadi A, El-Wakil $M \quad R$, Salam El-Okby and Selim O (1990): The Use Of Rapid Urease Test In Diagnosis Of Campylobacter Pylori Among Non-Ulcer Dyspepsia Patients In Egypt. J. Trop Med ;2:55-59.

13. Farinati F., De Bona M.,and Floreani A., (1998): Helicobacter Pylori And The Liver: Any Relationship? Ital J Gastroenterol Hepatol 30: 124-8.

14. Fiocca R., Villain Li. and Luinetti O., (1992): Helicobacter Colonization And Histopathological Profile Of Chronic Gastritis In Patients With Or Without Dyspepsia, Mucosal Erosion And Peptic Ulcer: A Morphological Approach To The Study Of Ulcerogenesis In Man. Arch A Pathol Anat Histopathol 4209;489-98.

15. Gadalla H., Abdel Moezz A ,and El Tony, (2001): Estimation Of Serum And Tissue Level Of Il-8, Adenosine Deaminase And Super Oxide Dismitate In Gastric Disorders Assoaciated With Helicobacter Pylori Infection. Az J Microbial 51: 116-128
16. Ge Z.,and Taylor D., (1999): Genome Sequence To Under Stand H. Pylori : Ann Review Of Microbiology. 53:353-387.

17. Graham D. Y., R. M., (1994): Reinfection With Helicobacter Pylori. In: Hunt R H, Tytagat G N J, Eds. Helicobacter Pylori: Basic Mechanisms To Clinical Cure. Dordrescht: Kluwer Academic Poblishers, 113-20.

18. Graham D. Y., Lew G. M., Klein P. D., Evans D. G., Sueed Z. A., And Malaty H. M. (1992): Effect Of Treatment Of H P Infection On The Long-Term Recurrence Of Peptic Ulcer. Am. Intern. Med.; 166(9): 705-8.

19. Gubbins G..P., Moritz T. E., Marsano L. S., (1993): Helicobacter Pylori Are A Risk Factor For Hepatic Encephalopathy In Acute Alcoholic Hepatitis: The Ammonia Hypothesis Revisited. Am J Gastroenterol; 11:1906-10.

20. Harris P. R., Mobely H. L. T.; Petez - Petez G. L.; Blaser M. J.,and Smith P.P. (1996): H. Pylori Urease Is A Potent Stimulus Of Mononuclear Phagocyte Activation And Inflammatory Cytokine Production. Gastroenterology III:419-425.

21. Hopkins $\mathbf{R}$ J. Girardi $\mathbf{L} \mathbf{S}$ and Turney E A (1996): Relationship Between Helicobacter Pylori Eradication And Reduced Duodenal And Gastric Recurrence: A Review. Gastroenterology; 110:1244-1252.

22. Kim J S, Jung H C. Kim J M, Dong I S, and Kim C Y (1998): Interleukin -8 Expression By Human Neutrophils Activated By Helicobacter Soluble Proteins. 
Scand J Gastroenterol Dec; 33 (12): 1249-55.

23. Kotkat A, Naficy A, Hyams KC and Clemens $J$ (1999): Seroprevalence Of $\mathrm{H}$. Pylori Among Egyptian Newborns And Their Mothers: A Preliminary Report. AM J Trop Med Hyg ; 61:37-40.

24. Mc Cormick, P.A. ; Sankey, E.A.; Cardin, F.; Dhillon, A.P. Mcintyre, N. and Burroughs, A.K. (1991): Congestive Gastropathy And HP: An Endoscopic And Morphometric Study. Gut, 32, No. 4 : P. 351 354.

25. Miyaji H., Azuma. T.,and Lto Y., (1997): Effects Of H. Pylori Eradication Thearapy On Hyperammonemia In Patients With Livert Cirrhosis. Gut; 40: $726-30$.

26. Mosatafa S.M., Zakaria M.S.,and El Razik. S., (1993): Prevalence Of H. Pylori In The Gastropathy Of Portal Hypetension. Thesis Submitted In Partial Fulfillment Of Master Degree In Tropical Medicin. Cairo University Result. $106-133$, Discussion P. 136-144.

27. Mounir B I, Khedr H F, Erina $Y R$ and El-Serafy M A (2000): Gastric Mucosal Morphology And Helicobacter Pylori In Various Age Groups. Endoscopy (Arab Edition) 1:45-50.

28. Naumovski-Mihalie S, Colic Cvrtje V, Prskato M, Saboric B and Tick $M$ (2000): Helicobacter Pylori Infection In Patients With Liver Cirrhosis. Gut;47 (Supp III): A 101.

29. Negrini R., Sabio A., Poiesi C., (1996): Antigenic Mimicity Between Helicobacter Pylori And Gastritis In The Pathogenesis Of
Body Atrophic Gastritis. Gastroenterology; 111: 655-65.

30. Omar Mm, El-Ansary M, Mostafa I, Aki M, El-Sherbini E, El-Badrawy $\mathbf{N}$ And Hunter $M$ $S$ (1997): Helicobacter Pylori Among Egyptian Patients With Chronic Liver Disease. A Comparative Study. J. Egypt Soc Parasitol; 27: 563-70.

31. Osaki T, Yamaguchi H, Taguchi H, Fukada M, Kawakami H, Hirano H, Kamiya S. (2002): Interleukin - 8 Induction And Adhesion Of The Coccoid Form Of Helicobacter Pylori. J Med Microbio1. 51(4): 295-9.

32. Parsonnet J (1995): The Incidence Of Helicobacter Pylori Infection. Aliment Pharmacol Ther; 9:45-51.

33. Piccirillo, M.M. and Gigliotti, T. (1991): Gastric Antral Erosions And $\mathrm{Hp}$ Infection In Cirrhotic Patient. Ital. J. Gastroenterol., 23 (3): 132-5.

34. Pisani P, Parkin $\mathbf{D} M$ and Muno Z N (1997): Cancer And Infection: Estimates Of The Attributable Fraction In 1900. Cancer Epidemiology. Biomarker And Prevention; 6:389-4000.

35. Ponzetto A, Pellicano (2000): R, Leone N, Cutufia M A, Turrini F and Grigioni W F Helicobacter Pylori Infection And Cirrhosis In Hepatitis C Virus Carriage: Is It An Innocent Bystander Or A Troublemaker? Med Hypotheses; 54:275-7.

36. Pugh T (1973): Quoted from diseases of liver and biliary tract (1998) $9^{\text {th }}$ ed blackwall science London

37. Schmulson M J, De Leon G, Kershenovic A, Vagas Vorackova And Kershenobich D (1997): Helicobacter Pylori 
Infection Among Patients With Alcohol And Non-Alcohol Cirrhosis. Helicobacter; 2:149-51.

38. Shaheen, Y. A., (1993): Endoscopic And Pathologic Appearance Of The Gastric Mucosa In Patients With Chronic Liver Disease. M. Sc. Thesis (Tropical Medicine ), Zagazig Univ.

39. Siringo S., Vaira D., Menegatti M., (1997): High Prevalence Of Helicobacter Pylori In Liver Cirrhosis Relationship With Clinical And Endoscopic Features And The Risk Of Peptic Ulcer. Dig Dis Sci; 42:2024-30.

40. Takahashi S, Nakamura E, Okabe S (1998): Effect of cytokines, without and with Helicobacter pylori components, on mucus secretion by cultured gastric epithelial cells. Dig Dis Sci; 43 (10): 2301-8

41. Tsai C J (1998): Helicobacter Pylori Infection And Peptic Ulcer Disease In Cirrhosis. Dig Dis Sci ;43: 1219-1225.

42. Vaira D., Stanghellini V,M Menegatti M., (1997): Prospective Screening Of Dyspeptic Patients By Helicobacter Pylori Serology: A Safe Policy ? Endoscopy 29: 595601.
43. Wu C S, Lin C Y and Liaw Y (1995): Helicobacter Pylori In Cirrhosis Patients With Peptic Ulcer Disease: A Prospective, Case Control Study. Gastroenterol Endosc; 42:424-7.

44. Wu C. Y. Poons K., and Genda H., (1998): Interaction Between H. Pylori And N S A I Ds In Peptic Ulcer Bleeding. Scabd J. Gastroenterol; 33:234-237.

45. Yamaoka Y, Kita M, Kodama T, Sawai N, and Kashima K, Imanishi J (1997): Induction Of Various Cytokines And Development Of Severe Mucosal Inflammation By Cag A Gene Positive Helicobacter Pylori Strains. Gut 41 (4): 442-51.

46. Yamaoka Y., Kodama T.,and Kashima K., (1998): Variants Of The 3 Region Of The Cag A Gene In Helicobacter Pylori Isolates From Patients With Different $\mathrm{H}$. Pylori- Associated Diseases. J Clin Microbial; 36: 2258-63.

47. Yoshikawa N., Yamamura F., and Akita Y., (1999): The Significance Of Serum Anti-Cag A Antibody In H. Pylori Infected Patients With Peptic Ulcer In Japan. Gut Vol. 45 Supp No. Page A 188. 
دراسة العلاقة بين الإصابة بالميكروب العلزونى ومادة الانترلوكين

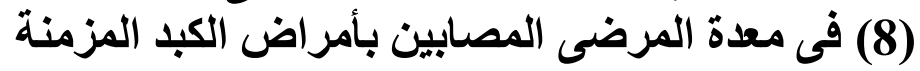

\section{محسن محمد الخياط، زينب نبيل سعيد*، جمال سعد الايب، هانى سعيد صبرى، ممدوح

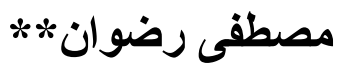

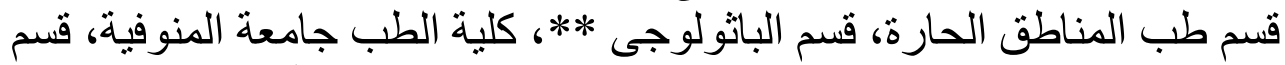
الميكروبيولوجى *، كلية الطب (بنات) جامعة الأزهر الطر

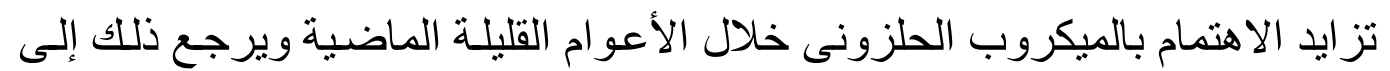

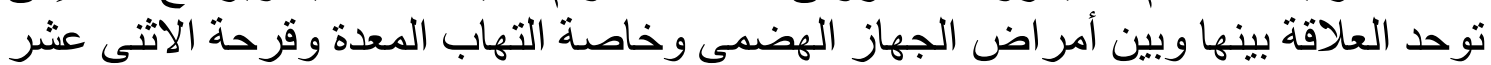
وسرطان المعدة.

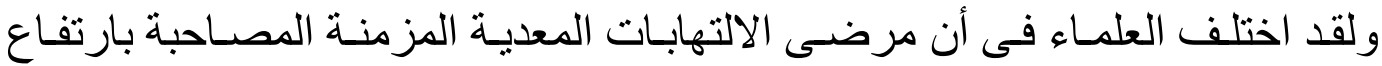

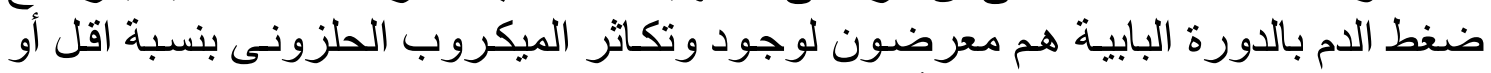

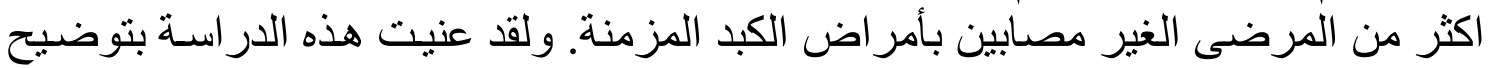

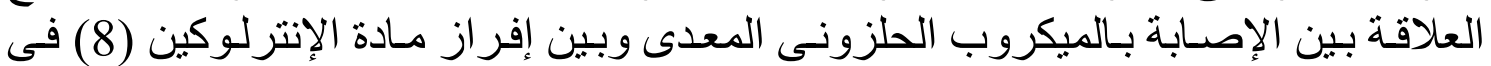

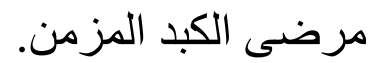

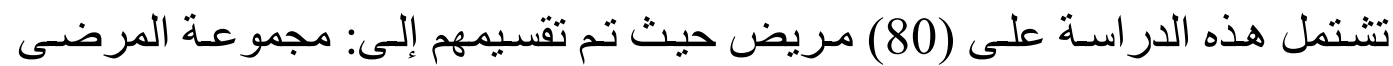

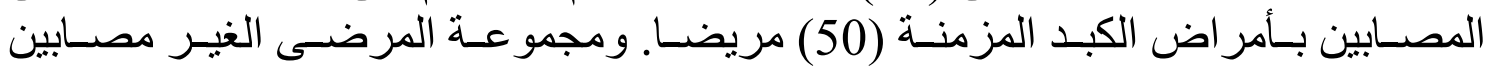
بأمر اض الكبد المزمنة

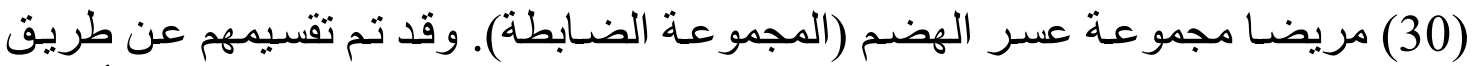

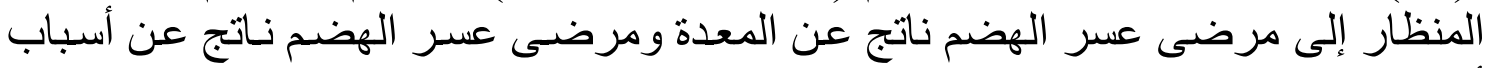

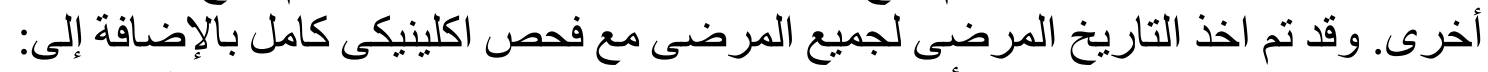

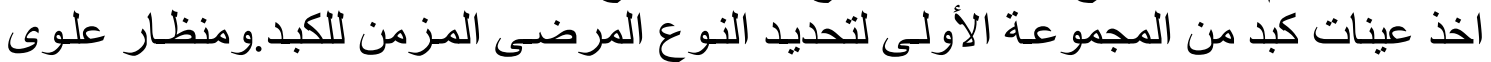

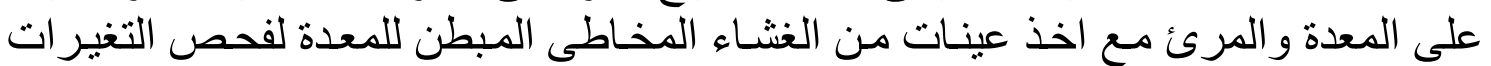

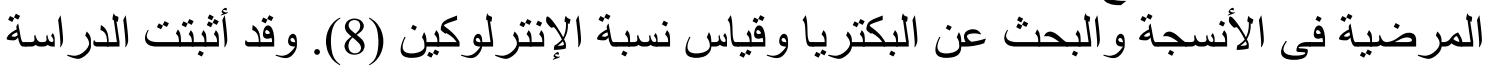

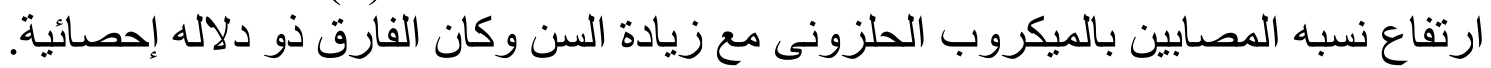

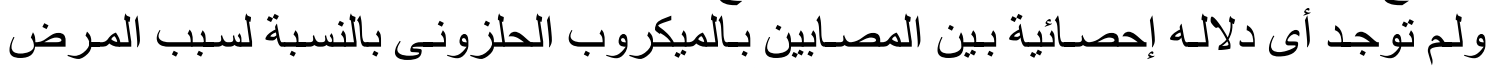

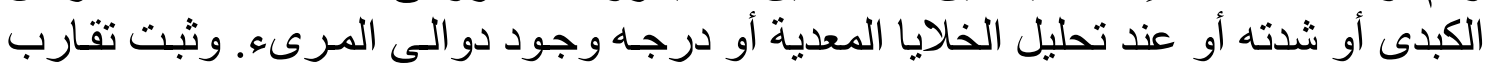

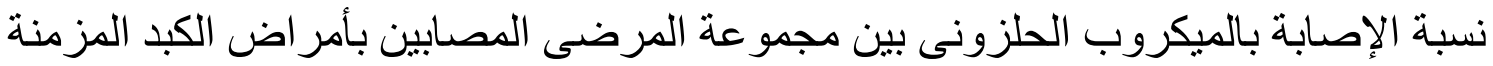

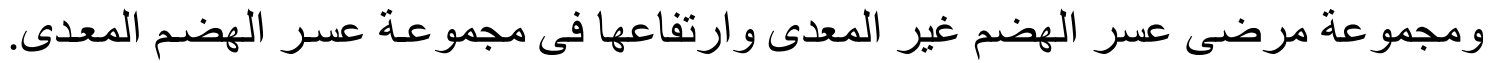

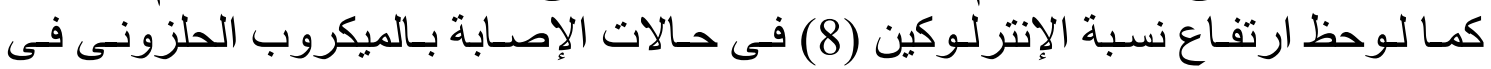

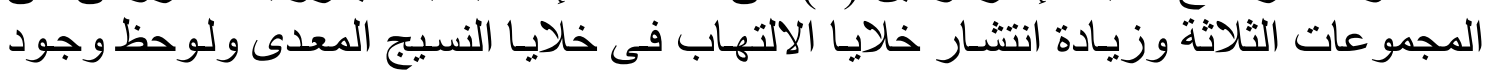

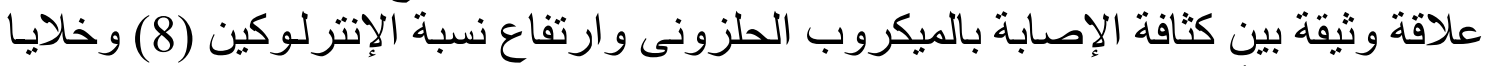

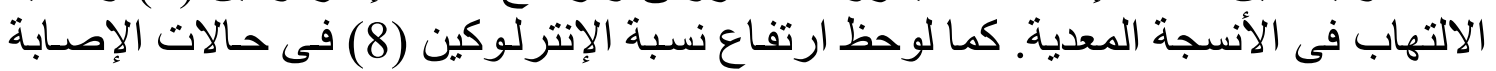

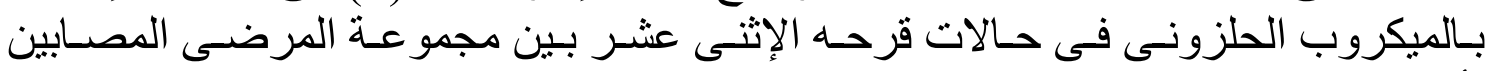

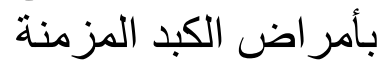

